\title{
Using Cone Beam, Micro- And Nano- Computed Tomography in Endodontic Treatment
}

\author{
Betul Aycan Alim (Corresponding author) \\ Bezmialem Vakif University Faculty of Dentistry, Department of Endodontics, Istanbul, Turkey \\ E-mail: balim@bezmialem.edu.tr \\ Yildiz Garip Berker \\ Istanbul Kent University Faculty of Dentistry, Department of Endodontics, \\ Istanbul, Turkey \\ Mehmet Burak Guneser \\ Bezmialem Vakif University Faculty of Dentistry, Department of Endodontics, \\ Istanbul, Turkey \\ Asiye Nur Dincer \\ Bezmialem Vakif University Faculty of Dentistry, Department of Endodontics, \\ Istanbul, Turkey
}

We accepted that submission is not being considered elsewhere. There is no conflict of interests.

\begin{abstract}
Many factors such as dental anatomy, root canal structure, localization of pathologies, biomechanical instrumentation and filling of the root canal affect the success of endodontic treatment. The use of radiographs is an important part of endodontic treatment. Resorption, root fracture, presence and location of lateral canals, determination of bone fenestrations, adaptation of root canal filling materials postoperatively, lesion follow-up, healing in periradicular tissues, imaging of bones and teeth in case of trauma are needed in three-dimensional imaging. Morphology of root canals, changes in root canal after instrumentation, root canal filling can be evaluated in three dimensions with micro-CT technique. NanoBT is an up-to-date imaging method that uses a high-power X-ray source with only a few micron focal points. The aim of this review is to evaluate the advantages and disadvantages of cone beam, microcomputed tomography and nano-computed tomography which is a new technology in endodontics.
\end{abstract}

Key words: endodontics, cone-beam tomography, micro-computed tomography, nano-computed tomography

DOI: $10.7176 / \mathrm{JSTR} / 5-6-03$

\section{Endodontik Tedavide Konik Işınlı, Mikro Ve Nano Bilgisayarlı Tomografinin Kullanımı}

Özet

Diş anatomisi, kök kanal yapısı, patojenlerin lokalizasyonu, kök kanalının biyomekanik enstrumentasyonu ve doldurulması gibi birçok etken endodontik tedavinin başarısını etkilemektedir. Radyograf kullanımı, endodontik tedavinin önemli bir parçasıdır. Rezorpsiyon, kök kırı̆̆ı, lateral kanalların varlığının ve yerinin tespit edilmesi, kemik fenestrasyonlarının belirlenmesi, postoperatif olarak kanal dolum materyallerinin adaptasyonu, lezyon takibi, periradiküler dokularda ki yara 
iyileşmesi, travma durumunda kemik ve dişlerin görüntülenmesi gibi bir çok durumda üç boyutlu görüntülemeye ihtiyaç duyulmaktadır. Mikro-BT tekniği ile kök kanallarının morfolojisi, enstrumentasyon sonrası kök kanalındaki değişiklikler incelenebilir, kök kanal dolumu üç boyutlu olarak detaylı şekilde değerlendirilebilir. Nano-BT ise, sadece birkaç mikron odak noktası olan, yüksek güçlü bir X-ışını kaynağı kullanan güncel bir görüntüleme yöntemidir. $\mathrm{Bu}$ derlemenin amacı, endodonti alanında konik ışınlı, mikro bilgisayarlı ve henüz yeni bir teknoloji olan nano bilgisayarlı tomografinin kullanımı, avantaj ve dezavantajlarının değerlendirilmesidir.

Anahtar Kelimeler: endodonti, konik ışınlı bigisayarlı tomografi, mikro bilgisayarlı tomografi, nano bilgisayarlı tomografi

\section{Giriş}

Başarılı bir kök kanal tedavisi tedavi için gerekli olan üç faktör; doğru teşhis, yeterli kemomekanik preparasyon ve kök kanal boşluğunun apikale kadar hermetik olarak doldurulmasıdır (Hession, 1981; Özsezer, 2004). Her adımın radyografik olarak değerlendirilmesi başarıyı artıran önemli bir etkendir. Periapikal radyograflar tedaviden önce, tedavi sırasında ve sonrasında görüntülemede en doğru ve en az subjektif sonucu veren tanı araçlarıdır. Analog bir film ya da dijital bir reseptör kullanılan konvansiyonel X-ışınları, üç boyutlu bir nesnenin, iki boyutlu görüntüsünü üretmektedir. Dişi çevreleyen yapılar superpoze olduğu için radyografiyi yorumlamak bazı durumlarda zor olabilmektedir (Goldman ve diğ.,1972; Goldman ve diğ., 1974; Deepak ve diğ., 2012; Kiarudi ve diğ., 2015;). Radyograf kullanımı endodontik tedavinin önemli bir parçası olmasına rağmen, rutin radyografik prosedürler lezyonun varlığını, gerçek boyutunu veya anatomik yapılarla ilişkisini doğru olarak gösteremeyebilir (Deepak ve diğ., 2012; Cotti ve diğ. 2002). Bu nedenle çeşitli görüntüleme yöntemlerinin endodonti alanında kullanımı geliştirilmiştir.

Bu makalenin amacı, endodonti alanında konik ışınlı bilgisayarlı tomografi (KIBT), mikro bilgisayarlı tomografi (Mikro-BT) ve henüz yeni bir teknoloji olan nano bilgisayarlı tomografinin (nano-BT) kullanımı, avantaj ve dezavantajlarının derlenmesidir.

\section{Konik Işınlı Bilgisayarı Tomografi}

Endodontide, KIBT kullanımı ilk olarak 1996 yılında gerçekleştirilmiştir. KIBT’nin en önemli avantajı; intraoral, panoramik ve sefalometrik olarak görüntülenemeyen yapıların üç boyutlu olarak görüntülenebilmesidir. X-Ray ışını kullanılarak üç boyutlu görüntüleme yapılması odontojenik ve nonodontojenik patojenlerin teşhisi, kök kanalının biyomekanik enstrumentasyonu ve doldurulması gibi endodontinin tüm alanlarında bize katkı sağlamaktadır (Scarfe ve dĭ̆., 2009). Doğruluk oranının yüksek olması, yüksek çözünürlük ve tarama süresinin çok uzun olmaması en önemli üstünlükleridir (Cotton ve diğ., 2007).

Yapay kemik defektlerinde iki ve üç boyutlu görüntülerin kullanımını karşılaştıran araştırmaların sonucuna göre, KIBT'nin kemik defektlerinin saptanmasında ve sınıflandırılmasında \%80-100'lük bir duyarlılığa sahip olduğu tespit edilirken, intraoral radyografilerin \%63-67'lik bir hassasiyet gösterdiği bulunmuştur. Ayrıca, KIBT' nin sunduğu boyutların gerçek boyutlarla uyumlu olduğu görülmüştür (Scarfe ve diğ., 2008; Fuhrmann ve diğ. 1995; Vandenberghe ve diğ., 2007).

Türkiye'de yapılan bir çalışmada, endodontistlerin \%66.7 sinin KIBT hakkında bilgi sahibi olduğu, bu grubun \%41.9 unun daha önce KIBT tercih ettiği öğrenilmiştir. KIBT tercih etme nedenleri arasında: \%82.4 kist-tümör, \%71.6 implant planlanmas1, \%50 travma, \%32.4 rezorpsiyon bölgesinin gösterilmesi, \%25.7 kök kanal morfolojisinin değerlendirilmesi, \%16.2 sinin kırık aletin yerinin tespit edilmesi bulunmaktadır (Yalcinkaya ve diğ., 2014).

KIBT; diş morfolojisi, kanal sayısı, pulpa odasının boyutları, mevcut olan kalsifikasyonların derecesi, kök yapısı, iatrojenik defektler, çürük varlığı, internal ve eksternal rezorpsiyon derecesini

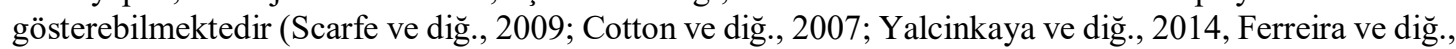
2013). Ek olarak dens in dente ve dilasere köklerin teşhisinde periapikal radyograflara göre daha etkilidir. Apikal periodontitis ve özellikle küçük lezyonlar daha doğru teşhis edilebilir. Endodontik cerrahi planlamasında ve dişin çevre anatomik yapılarla olan komşuluğunu tespit etmede de oldukça önemlidir. Maksiller sinüs ve sinüzitin potansiyel nedenleri de daha doğru görüntülenebilmektedir (Venskutonis ve diğ., 2014).

Kanal içi kalsifikasyonların görüntülenmesi, lateral kanalların varlığının ve yerinin tespit edilmesi, kemik fenestrasyonlarının belirlenmesi, postoperatif olarak kanal dolum materyallerinin adaptasyonu, lezyon takibi, periradiküler dokularda ki yara iyileşmesi, travma durumunda kemik ve dişlerin görüntülenmesi için KIBT tercih edilmektedir (Scarfe ve diğ., 2009; Venskutonis ve diğ., 2014, Todd, 2014). Yapılan 
son çalışmalarda KIBT'nin biyopsi ve histolojik tanı ile kıyaslandığında büyük periapikal lezyonların değerlendirilmesinde daha doğru sonuç verdiği görülmektedir (Simon ve diğ., 2006).

KIBT, kök rezorbsiyonunun varlığını ve yerini gösterebilmektedir. Perforasyonların ve yer değiştirmemiş kök kırıklarının intraoral radyograflarda teşhis edilmesi zor olabilmektedir ve bu tür vakaların doğru teşhis edilmeleri, tedavi planlaması ve prognoz için oldukça önemlidir. KIBT ile görüntüleme perforasyonların, kırı aletlerin ve döküm post deviasyonların daha doğru tespit edilmesini sağlarken vertikal kök kırıklarının teşhisinde KIBT ile teşhis günümüzde hala belirsizdir. Horizontal kök kırıklarının teşhisi, kırık mezodistal yönde olduğu için daha kolay yapılabilmektedir (Venskutonis ve diğ., 2014). KIBT görüntüleri, diğer tanı yöntemlerindeki gibi, görüntünün aslına uygunluğunu etkileyen artefaktlara duyarlıdır. Artefaktlar dört kaynağa bağlı oluşabilir: 1- hasta; 2- tarayıcı; 3- KIBT sistemine özgü artefaktlar ve 4- 1şın sertleşmesi olarak bilinen X ışını artefaktları. Metal restorasyonlar, postlar, pinler ve dental implantlar artefakt oluşturabilir. Metal artifaktlar özellikle baş boyun bölgesinde daha çok görülmektedir (Scarfe ve diğ., 2009; Pauwels ve diğ., 2013).

\section{Mikro Bilgisayarlı Tomografi}

Mikro-BT tekniği ile kök kanallarının incelenmesi ilk olarak 1995 yılında gerçekleştirilmiştir. MikroBT' nin sayısız avantajı vardır. Sonuçlar tekrarlanabilmekte ve histolojik kesitlerle kıyaslanabilmektedir. Mikro-BT tekniği ile kök kanallarının morfolojisi, enstrumentasyon sonrası kök kanalındaki değişiklikler incelenebilir, kök kanal dolumu üç boyutlu olarak değerlendirilebilir (Lopez-Rosales ve diğ., 2015; Jung ve diğ., 2005; Swain ve Xue, 2009; Nielsen ve diğ., 1995). Mikro-BT sistemlerinin kullanılabilirliği ile kök kanal morfolojisi non-invaziv ve hassas bir şekilde incelenebilir. İç ve dış anatomi aynı anda veya ayrı ayrı gösterilebilirken görüntüler kalitatif ve kantitatif olarak değerlendirilebilir. Pulpa odası, kök kanallarının morfolojisi, anatomik varyasyonlar ve lateral kanallar görüntülenebilir (Jung ve diğ., 2005; Swain ve Xue , 2009). 19 mikron kadar küçük voksel boyutları ile 3D görüntüler elde edilebilir (Nielsen ve diğ., 1995). Son yıllarda, Mikro-BT sistemi kantitatif olarak, 5 ile 30 mikron arasında bir çözünürlüğe sahip olan kemik ve dişlerin mineral konsantrasyonunu ölçmek için de kullanılmaya başlanmıştır. MikroBT, yeniden yapılandırılmış, nano boyutlu kesitlerin çok daha küçük bir ilgi alanına odaklanması dışında KIBT'ye benzemektedir. Konik-1̧̧ın geometrisini kullanan cihazların görüntü kalitesi, milliamper, kilovoltaj ve voksel boyutu gibi parametrelere göre değişir (Swain ve Xue , 2009). Voksel boyutu Xışını mikro-tomografisinde önemli ölçüde küçük olabileceğinden, bu parametrelerin uygun ayarları daha yüksek çözünürlüklü, düşük gürültülü görüntülerin elde edilmesi için çok önemlidir (Peyrin and Engelke, 2011). Maksiller ve mandibular dişlere ait kök kanallarının Mikro-BT görüntülerinde aksesuar kanalların varlığı altın standart olarak kullanılan stereomikroskop görüntüleri ile istatistiksel olarak anlamlı bir korelasyon göstermiştir. Mikro-BT, KIBT kullanılarak elde edilenden daha yüksek bir çözünürlüğe sahip görüntüler sağlar ve bu nedenle küçük yapıları görselleştirmek için daha uygundur. Süt dişlerinde yapılan bir çalışmada aksesuar kanalların üç boyutlu görüntülenmesinde Mikro- BT, KIBT' ye göre daha başarıı ı bulunmuştur (Acar ve diğ., 2015). Domark ve arkadaşlarının kadavraların maksiller 1. molar dişleri üzerinde yaptıkları Mikro- BT çalışmasında $\mathrm{MB}^{2}$ kanalının tespit edilmesi \%100 olarak bildirilmiştir (Domark ve diğ., 2013).

Bütün olumlu özelliklerine rağmen Mikro-BT kullanmanın bazı kısıtlamaları da görülmektedir. Teknisyenin zamanı, tarama ve görüntü ölçümlerini manipüle etmek için yazılımın maliyeti MikroBT'nin dezavantajları arasındadır (Jung ve diğ., 2005; Swain ve Xue, 2009; Nielsen ve diğ., 1995; Acar ve diğ., 2015). KIBT, in vivo çalı̧̧malarda da kullanılabilirken Mikro- BT' nin sadece in vitro çalışmalarda kullanılması en belirgin dezavantajıdır (Rhodes ve diğ., 1999; Acar ve diğ., 2015). In-vivo micro-BT, küçük hayvan modellerinde pulmoner ve kardiyak performans parametreleri için fonksiyonel bir teşhis yöntemi olarak kullanılmıştır (Badea ve diğ., 2004; Lee ve diğ., 2014). Fakat diş hekimliği alanında in vivo Mikro-BT kullanımına bağlı henüz bir çalışma mevcut değildir.

\section{Nano Bilgisayarlı Tomografi}

Son zamanlarda, sadece birkaç mikron odak noktası olan, yüksek güçlü bir X-1̧̧ını kaynağı kullanan, nanometre ölçekli X-ışıı BT (nano-BT) kullanılmaya başlanmıştır (Withers, 2007). Genel olarak nanofokal spot kaynağ $(<400 \mathrm{~nm}$ ) kullanan Nano-BT sistemleri (Peyrin ve diğ., 2014) kıkırdak ve kemik dokuları, materyal kalitesini ve damar ağlarının görüntülenmesini analiz etmek için kullanılmaya başlanmıştır (Kerckhofs G ve diğ., 2013; Kerckhofs G ve diğ., 2014; Van Hove ve diğ., 2009; Cuijpers ve diğ., 2014; Salmon ve Sasov, 2007). Bununla birlikte, ortaya çıkan bu güçlü görüntüleme yöntemi ile şimdiye kadar endodonti alanında yapılmış çok az çalışma mevcuttur. Huang ve arkadaşları, kök kanal dolum kalitesini mikro-BT ve nano-BT görüntüleme yöntemlerini kullanarak incelemişlerdir. Her iki yöntemde kök kanalının içyapısının gözlemlenmesine izin verse de, nano-BT görüntülemenin, kök kanal

21 I P a g e 
dolumu içindeki boşluk hacminin tespit edilmesinde daha başarılı olduğunu bulunmuştur (Huang ve diğ., 2017).

Orhan ve arkadaşları, Mikro-BT $(5.2,8.1,11.2$ ve $16.73 \mu \mathrm{m})$ ve Nano-BT $(1.5$ ve $5.0 \mu \mathrm{m})$ ile farklı voksel boyutları kullanarak kök kanal dolum kalitesini değerlendirmişlerdir. Çalışmanın sonucunda, mikro-BT görüntülerinde, boşluk olan bölümlerin voksel çözünürlükleri arasında önemli farklılıklar olduğunu tespit edilirken, nano-BT görüntülerinde farklı voksel boyutlarında yapılan görüntülemede anlamlı bir fark bulunamamıştır (Orhan ve diğ., 2018).

Endodonti alanında, yakın zamanda yapılan bir çalışmada, servikal kök rezorpsiyonunu incelemek için histolojik değerlendirme ile birlikte mikro ve nano-BT kullanılmıştır. Sonuçlar, nano-BT'nin onarıcı doku ve dentin arasındaki sınırı açıkça belirleyebildiğini doğrulamıştır. Görüntü çözünürlüğü aynı zamanda doku düzeyindeki histolojik değerlendirmeyle eşleşmiştir. Fakat nano-BT teknolojisinin de belli sınırlamaları mevcuttur. Yüksek maliyetine ek olarak, özellikle hücresel değerlendirmeler için özel boyama gerektiğinde histolojik değerlendirmenin yerini alamayacağı düşünülmektedir. Optimal parametreler de pilot deneyler gerektirebilmektedir (Mavridou ve diğ., 2016).

Tüm bu literatür bilgilerinin ışığında, KIBT' nin in vivo olarak kullanılabilmesi, teknik ve biyolojik açıdan değerlendirildiği zaman daha fazla güvenlik sağlaması, daha kolay ulaşılabilmesi ve maliyetinin mikro-BT ve nano-BT' ye göre daha düşük olması oldukça avantaj sağlamaktadır. In vitro çalışmalarda ise Mikro BT, daha detaylı görüntü oluşturabilme avantajı sayesinde verilerin daha doğru analiz edilmesine olanak sağlamaktadır. Mikro-BT, günümüzde hala güncelliğini koruyan ve endodontik çalışmaların her alanında kullanılabilen bir görüntüleme yöntemidir. Son olarak nano-BT, endodonti alanında henüz kullanılmaya başlanmış, ilerleyen zamanlarda yeni yapılacak çalışmalarla beraber mikroBT'nin önüne geçeceği tahmin edilen bir görüntüleme yöntemidir. Ancak, nano-BT' nin endodontik görüntüleme alanında desteklenmesi için çok daha fazla çalışmaya ihtiyaç duyulmaktadır.

\section{Kaynaklar}

Acar B, et al. Comparison of micro-computerized tomography and cone beam computerized tomography in the detection of accessory canals in primary molars. Imaging Sci Dent 2015; 45(4):205-11.

Badea C, Hedlund LW, Johnson GA. Micro-CT with respiratory and cardiac gating. Med Phys 2004; 31: 3324-3329.

Cotti E, Campisi G, Garau V, Puddu G. A new technique for the study of periapical bone lesions: Ultra sound real time imaging. Int Endod J 2002; 35:148-52.

Cotton TP, Geisler TM, Hoden DT, Schwartz SA, Schindler WG. Endodontic application of cone beam computed tomography. J Endod 2007; 33:1121-32.

Cuijpers VM, et al. Resolution, sensitivity, and in vivo application of high-resolution computed tomography for titanium-coated polymethyl methacrylate (PMMA) dental implants. Clin Oral Implants Res 2014; 25:359-365.

Deepak BS, Subash TS, Narmatha VJ, Anamika T, Snehil TK, Nandini DB. Imaging Techniques in Endodontics: An Overview. J Clin Imaging Sci 2012; 2: 13.

Domark JD, Hatton JF, Benison RP, Hildebolt CF. An ex vivo comparison of digital radiography and cone-beam and micro computed tomography in the detection of the number of canals in the mesiobuccal roots of maxillary molars. J Endod 2013 Jul; 39(7):901-5.

Ferreira RI, et al. Detection of vertical root fractures by cone-beam computerized tomography in endodontically treated teeth with fiber-resin and titanium posts: an in vitro study. Oral Surg Oral Med Oral Pathol Oral Radiol 2013; 115:e49-e57.

Fuhrmann RAW, Wehrbein H, Langen HJ, Diedrich PR. Assessment of the dentate alveolar process with high resolution computed tomography. Dentomaxillofac Radiol 1995; 24:50-4. 
Goldman M, Pearson AH, Darzenta N. Endodontic success- who is reading the radiograph? Oral Surg Oral Med Oral Pathol 1972; 33:432-7.

Goldman M, Pearson AH, Darzenta N. Reliability of radiographic interpretations. Oral Surg Oral Med Oral Pathol 1974; 38:287-93.

Hession RW. Long-term evaluation of endodontic treatment: anatomy, instrumentation, obturationthe endodontic practice triad. $J$ Endod 1981; 14:179.

Huang Y, et al. Micro-CT and nano-CT analysis of filling quality of three different endodontic sealers. Dentomaxillofac Radiol. 2017 Dec; 46(8):20170223.

Jung M, Lommel D, Klimek J. The imaging of root canal obturation using micro-CT. Int Endod $J$ 2005; 38(9):617-26.

Kerckhofs G, et al. Contrast-enhanced nanofocus computed tomography images the cartilage subtissue architecture in three dimensions. Eur Cells Mater 2013; 25:179-189.

Kerckhofs G, et al. Contrast-enhanced nanofocus X-ray computed tomography allows virtual threedimensional histopathology and morphometric analysis of osteoarthritis in small animal models. Cartilage 2014; 5:55-65.

Kiarudi AH, Eghbal MJ, Safi Y, Aghdasi MM, Fazlyab M. The applications of cone-beam computed tomography in endodontics: a review of literature. Iran Endod J 2015; 10(1):16-25.

Lee CL, et al. Assessing cardiac injury in mice with dual energy-micro CT, 4D-micro CT, and micro SPECT imaging after partial heart irradiation. Int J Radiat Oncol Biol Phys 2014; 88: 686-693.

Lopez-Rosales E, et al. Unusual root morphology in second mandibular molar with a radix entomolaris, and comparison between cone beam computed tomography and digital periapical radiography: a case report. J Med Case Rep 2015:22;9(1):201.

Mavridou AM, et al. A novel multimodular methodology to investigate external cervical tooth resorption. Int Endod J 2016; 49:287-300.

Nielsen BR, Alyassin A, Peters DD, Carnes DL, Lancaster J. Microcomputed tomography: an advanced system for detailed endodontic research. J Endod 1995; 21:561-68.

Orhan K, et al. Evaluation of Threshold Values for Root Canal Filling Voids in Micro-CT and NanoCT Images. Scanning 2018:16; 9437569.

Ozsezer E. Endodontic Retreatment. GÜ Diş Hek Fak Derg 2004; 21(3): 217-222.

Pauwels R, et al. Quantification of metal artifacts on cone beam computed tomography images. Clin Oral Implants Res 2013; 24:94-99.

Peyrin F. and Engelke KCT, "Imaging: basics and new trends," in Handbook of Particle Detection and Imaging, C. Grupen and I. Buvat, Eds., p. 908, Springer Science \& Business Media, 2011.

Peyrin F, Dong P, Pacureanu A, Langer M. Micro- and nano-CT for the study of bone ultrastructure. Curr Osteoporos Rep 2014; 12:465-474.

Rhodes JS, Pitt Ford TR, Lynch JA, Liepins PJ, Curtis RV. Micro-computed tomography: a new tool for experimental endodontology. Int Endod J 1999; 32:165-70 
Salmon PL, Sasov AY. Application of nano-CT and high-resolution micro-CT to study bone quality and ultrastructure, scaffold biomaterials and vascular networks. In: Qin L, Genant HK, Griffith JF, Leung K, editors. Advanced bioimaging technologies in assessment of the quality of bone and scaffold materials. 1st ed. Berlin: Springer Verlag Heidelberg; 2007 p323-331.

Scarfe WC, Farman AG. What is cone-beam CT and how does it work? Dent Clin N Am 2008; 52:707-30.

Scarfe WC, Levin MD, Gane D, Farman AG. Use of cone beam computed tomography in endodontics. Int J Dent 2009; 634567.

Simon JH, et al. Differential diagnosis of large periapical lesions using cone beam computed tomography measurements and biopsy. J Endod 2006; 32:833-7.

Swain MV, Xue J. State of the Art of Micro-CT Applications in Dental Research. Int J Oral Sci 2009; 1(4):177-88.

Todd R. Cone beam computed tomography updated technology for endodontic diagnosis. Dent Clin North Am 2014 Jul; 58(3):523-43.

Withers PJ. X-ray nanotomography. Mater Today 2007; 10: 26-34.

Vandenberghe B, Jacobs R, Yang J. Diagnostic validity (or acuity) of 2D CCD versus 3D CBCT images for assessing periodontal breakdown. Oral Surg Oral Med Oral Pathol Oral Radiol Endod 2007; 104:395-401.

Van Hove RP, et al. Osteocyte morphology in human tibiae of different bone pathologies with different bone mineral density-is there a role for mechanosensing? Bone 2009; 45:321- 329.

Venskutonis T, et al: The importance of cone-beam computed tomography in the management of endodontic problems: A review of the literature. J Endod 2014; 40:1895- 1901.

Yalcinkaya SE, Berker YG, Peker S, Basturk FB. Knowledge and attitudes of Turkish endodontists towards digital radiology and cone beam computed tomography. Niger J Clin Pract 2014; 17:4718 . 